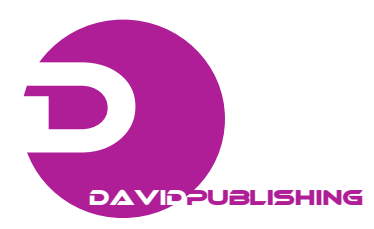

\title{
Application of Ceramic Membranes for Regeneration of Detergent Cleaning Solutions
}

\author{
Izabela Kowalska \\ Institute of Environment Protection Engineering, Wroclaw University of Technology, Wroclaw 50-370, Poland
}

Received: August 14, 2014 / Accepted: August 24, 2014 / Published: August 25, 2014.

\begin{abstract}
Pressure-driven membrane processes were investigated for the recovery of contaminated cleaning solutions (a single-phase detergent) emanating from a diary industry. The experiments were performed in a semi-pilot membrane installation in cross-flow regime. The filtration tests were carried out using tubular ceramic modules differing in cut-off value, with high resistance to chemical agents. The effect of long term filtration time and process conditions (transmembrane pressure, cross-flow velocity and temperature) on transport and separation properties of the modules was evaluated. The usefulness of ceramic modules for regeneration of a single-phase detergent for the purpose of its reuse in cleaning systems was revealed. The modules in a long-term filtration regime, due to their hydrophilic nature, were characterized by relatively low susceptibility to fouling. Rinsing modules with deionized water after filtration experiments helped significantly to restore their original permeability or cause even an increase of water flux in comparison with the stream of deionized water. The recovered spent detergent maintained its basic cleaning properties, i.e., high $\mathrm{pH}$, high concentration of $\mathrm{NaOH}$ and low value of surface tension. Moreover, the ceramic modules showed high retention of specific milk components (protein and lactose) and organic matter expressed as chemical oxygen demand (COD). It has been shown that the transport and separation properties of the modules were dependent on the process parameters, such as transmembrane pressure, cross-flow velocity and temperature.
\end{abstract}

Key words: Milk component, single-phase detergent, surface tension.

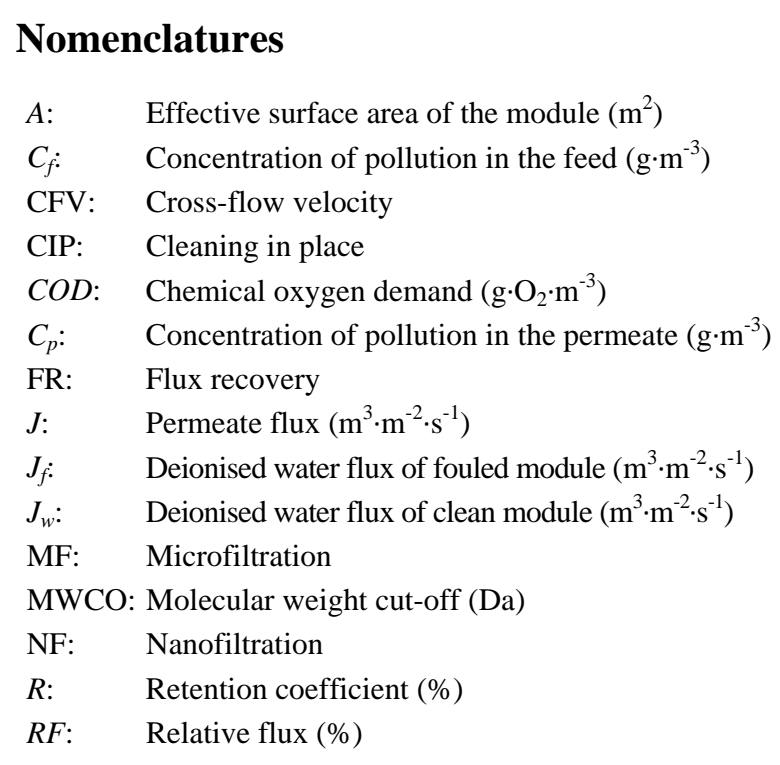

Corresponding author: Izabela Kowalska, Ph.D., research fields: pressure-driven processes in wastewater purification and water recycling and membrane hybrid processes. E-mail:izabela.kowalska@pwr.edu.pl.

\author{
$R_{m}: \quad$ Module resistance $\left(\mathrm{m}^{-1}\right)$ \\ $t: \quad$ Filtration time (s) \\ TMP: Transmembrane pressure \\ UF: Ultrafiltration \\ $V: \quad$ Volume of the permeate $\left(\mathrm{m}^{3}\right)$
}

\section{Introduction}

Pressure-driven membrane processes are widely employed in the dairy industry and the range of membranes' application has escalated in the last 30 years. Membrane processes are primarily used for microbial load reduction, fat reduction in whey protein concentrates, protein concentration or fractionation, partial demineralisation of the feedstock [1]. However, with the use of membrane techniques, which obtained the name of "green technologies", the recovery and reuse of a large volume of cleaning solutions within the food industry can also be realized. It leads to a reduction 
of spent chemicals discharged to environment and thus saving of chemicals, water and energy.

The food industry is a great consumer of chemicals, due to the nature of the production process and the need to maintain high standards of hygiene. According to the literature reports, the consumption of $\mathrm{NaOH}, \mathrm{HNO}_{3}$ and detergents in dairy industry of production on the level of 1,500 $\mathrm{m}^{3}$ milk/day, amounted to 3,500, 1,000 and $1,000 \mathrm{~kg} / \mathrm{day}$, respectively. The main load of pollutants discharged into the environment is related to the cleaning in place (CIP) systems [2].

The need for protecting the environment from the harmful effects of aggressive chemicals and the need for reducing water consumption during the washing process have brought about a change in the pattern of cleaning the production lines. Conventional methods for cleaning with the help of alkalis and acids are gradually being replaced by single-phase detergents. The composition of such a washing detergent includes alkalis or acids, surfactants, complexing and disinfecting agents, and defoamers. The recovery and reuse of cleaning chemicals within the food industry are of utmost importance. The analysis of literature data indicates that the membrane processes can be used for the purification and recovery of the cleaning solutions. However, the published research has mainly focused on the recovery of sodium hydroxide and nitric acid. The processes used for the recovery of chemicals were mainly nanofiltration (NF) [3-6], as well as ultrafiltration (UF) [7, 8] and microfiltration [9].

In the present paper, the results of the purification of contaminated cleaning solutions (a single-phase detergent) were reported. The effect of long term filtration time and process conditions (TMP, CFV and temperature) on transport and separation properties of UF was evaluated. Owing to the alkaline nature of the CIP solutions, the ceramic modules with high resistance to chemical agents were selected for the tests.

\section{Materials and Methods}

A liquid alkaline detergent, tailor-made for CIP systems in the dairy industry, was used. The single-phase detergent was composed mainly of sodium hydroxide with the addition of complexing agents and anionic surfactants. In the experiments spent model CIP solution was used. In order to simulate industrial conditions the solution was prepared by mixing $2 \% \mathrm{w} / \mathrm{v}$ aqueous solution of a single-phase detergent and $0.75 \% \mathrm{w} / \mathrm{v}$ of milk with a fat content of $3.2 \% \mathrm{w} / \mathrm{v}$ (solution $\mathrm{B}$ ). As a reference solution was tested, $0.75 \% \mathrm{w} / \mathrm{v}$ aqueous solution of milk with a fat content of 3.2\% w/v (solution A).

Tests in the cross-flow system were performed in a semi-pilot installation (Fig. 1). The main elements of the filtration installation were: the membrane module, a pump enabling circulation of the solution in the system, a $10 \mathrm{dm}^{3}$ capacity feed tank and thermostated water circulation. The filtration experiments were carried out using tubular ceramic modules CéRAM INSIDE® (Tami Industries) with high resistance to chemical agents (Table 1). The active layer of the module was zirconium dioxide coated on a porous membrane made of titanium dioxide.

Transport and separation properties of modules were examined within the range of temperature of $20-45^{\circ} \mathrm{C}$, transmembrane pressure of $0.25-6$ bar and the cross-flow velocity at the membrane surface of $1-10.5 \mathrm{~m} / \mathrm{s}$.

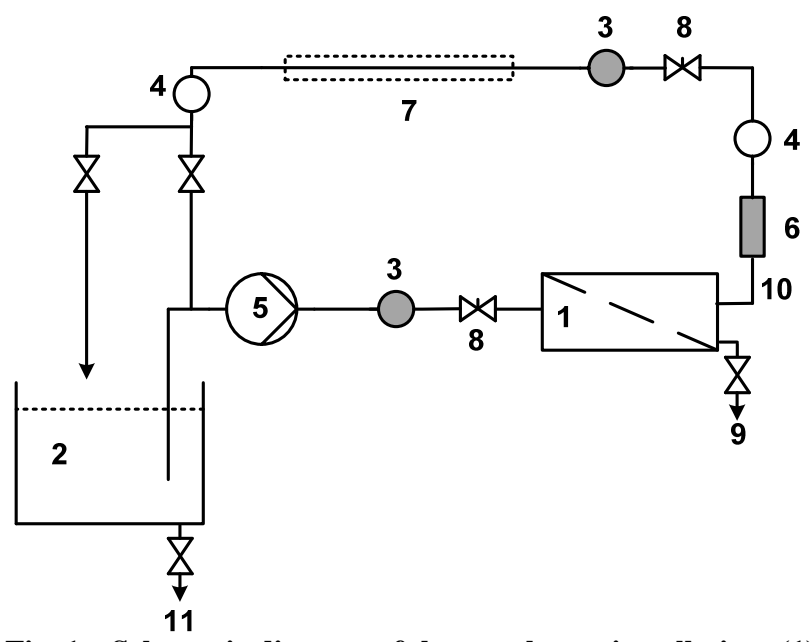

Fig. 1 Schematic diagram of the membrane installation: (1) membrane module, (2) feeding tank, (3) manometer, (4) thermometer, (5) pump, (6) rotameter, (7) cooler, (8) pressure regulation valve, $(9)$ permeate, $(10)$ retentate, $(11)$ drain valve. 
Table 1 Characteristics of the tubular ceramic membranes.

\begin{tabular}{llll}
\hline Parameter & \multicolumn{3}{l}{ Module } \\
\hline MWCO $(\mathrm{kDa})$ & 1 & 5 & 10 \\
Number of channels & 7 & & \\
Hydraulic diameter $(\mathrm{mm})$ & 2 & \\
Effective surface area $\left(\mathrm{m}^{2}\right)$ & 0.0130 & \\
Max. TMP (bar) & 10 & \\
Mechanical strength (bar) & $>90$ & \\
Chemical strength & $\mathrm{pH}=0-14$ \\
Max. Temperature $\left({ }^{\circ} \mathrm{C}\right)$ & $<350$ \\
\hline Deionised water flux of clean & 3.21 & 1.50 & \multirow{2}{*}{6.25} \\
module $^{\mathrm{a}} 10^{-5}\left(\mathrm{~m}^{3} \cdot \mathrm{m}^{-2} \cdot \mathrm{s}^{-1}\right)$ & 9.35 & 20.3 & 4.67 \\
$\mathrm{R}_{\mathrm{m}}\left(10^{12}\right),\left(\mathrm{m}^{-1}\right)$ & \multicolumn{3}{|l}{} \\
\hline
\end{tabular}

TMP $=3$ bar.

Table 2 Criteria for assessing the efficiency of the membrane process.

\begin{tabular}{ll}
\hline Parameter & Equation \\
\hline Retention coefficient (\%) & $R=\left(1-\frac{C_{p}}{C_{f}}\right) 100$ \\
Permeate flux $\left(\mathrm{m}^{3} \cdot \mathrm{m}^{-2} \cdot \mathrm{s}^{-1}\right)$ & $J=\frac{1}{A} \frac{d V}{d t}$ \\
Relative flux (\%) & $R F=\frac{J}{J_{w}} 100$ \\
Flux recovery (\%) & $F R=\frac{J_{f}}{J_{w}} 100$ \\
\hline
\end{tabular}

The criteria for assessing the effectiveness of the filtration process are the following parameters, listed in Table 2. The feed solutions and the permeates collected from the filtration runs were subjected to physicochemical analyses which have been described in the previous paper [10].

\section{Results and Discussion}

The relative flux of the ceramic modules is presented in Fig. 2. At the beginning of the membrane filtration cycle of the tested solutions, a reduction in permeate flux was noticed, in comparison with the flux of deionized water. However, with the filtration time, there were no further significant changes in the hydraulic performance of membranes. Ceramic UF modules were characterized by significant susceptibility to blocking by milk components (mainly proteins) during filtration of solution A $(0.75 \% \mathrm{w} / \mathrm{v}$ solution of milk). On average, permeate flux amounted to $30 \%, 60 \%$ and $35 \%$ of the initial flux of deionized water.

Similarly to the previous studies on the flat membranes [10], significantly higher values of relative flux was noticed for Solution B ( $2 \% \mathrm{w} / \mathrm{v}$ aqueous solution of the single-phase detergent to which was added $0.75 \% \mathrm{w} / \mathrm{v}$ of milk). A lower susceptibility of modules to fouling in a strongly alkaline environment ( $\mathrm{pH} \approx 13$ ) could be probably attributed to phenomenon of protein denaturation. According to the model proposed by Erdem and Yuksel [11], the denatured proteins form complexes with casein micelles causing an enlargement of them. The deposition of the large particles on a membrane surface results in formation of an additional sieving layer which helps to protect the membrane pores from fouling and congestion.
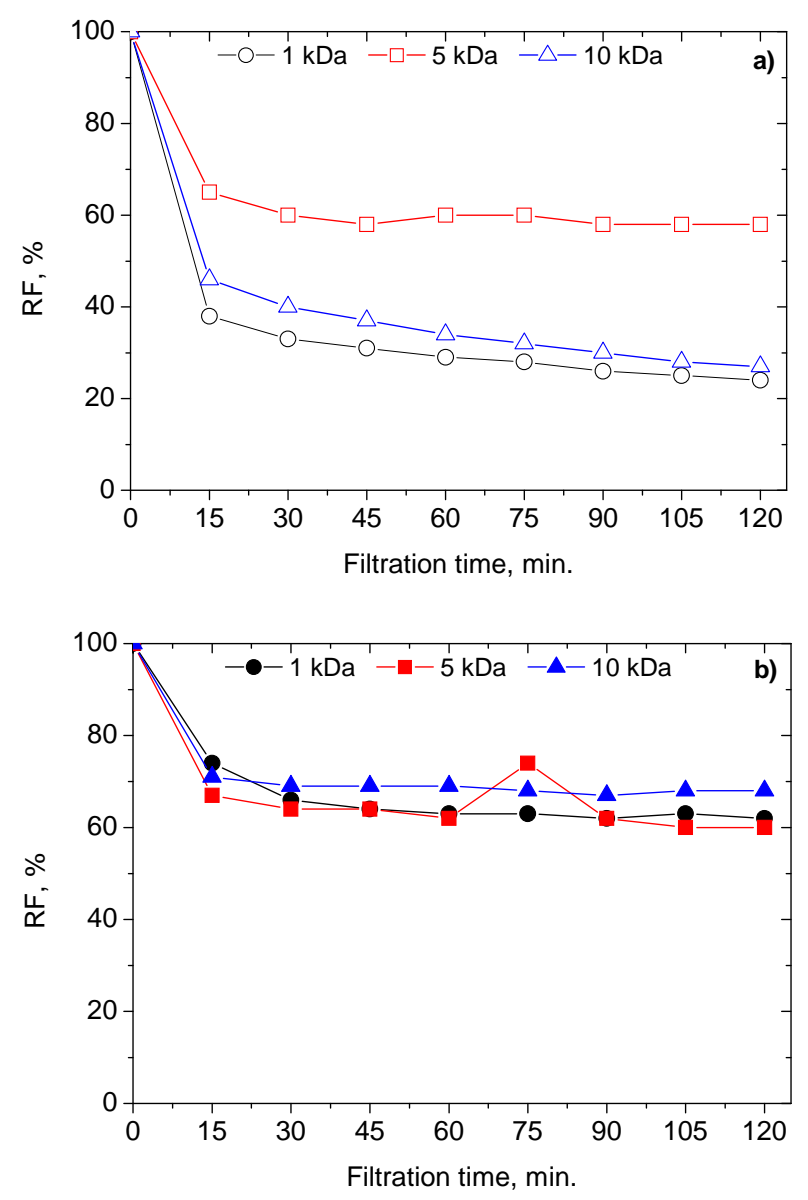

Fig. 2 Changes in the relative flux during the filtration cycle of (a) solution $A$ and (b) solution B. Process parameters: $1 \mathrm{kDa}$ : TMB $=3 \mathrm{bar}, \mathrm{CFV}=6.3 \mathrm{~m} / \mathrm{s}$; $5 \mathrm{kDa}$ : TMB = 3 bar, CFV = 2.5 m/s; 10 kDa: TMB = 2 bar, CFV = $6.3 \mathrm{~m} / \mathrm{s}$. 
Table 3 Flux recovery (FR, \%) of ceramic membranes after the rinsing step with deionized water.

\begin{tabular}{llc}
\hline Cut-off $(\mathrm{k} \cdot \mathrm{Da})$ & Solution A & Solution B \\
\hline 1 & 29 & 87 \\
5 & 84 & 110 \\
10 & 63 & 108 \\
\hline
\end{tabular}

Rinsing modules with deionized water after filtration cycle of solution $\mathrm{B}$, helped to significantly restore their original permeability or caused even an increase of water flux in comparison with the stream of deionized water (Table 3). However, the ceramic modules after filtration cycle of solution A (to which the effect of fouling was more pronounced), in a less extent recovered their original water flux. Thereby the additional regeneration step with the use of $0.1 \mathrm{~N}$ $\mathrm{NaOH}$ was required.

The feed solutions and the permeate collected at the intervals of every $15 \mathrm{~min}$ were subjected to physicochemical analyses. Ceramic modules operating in conditions of long-term filtration were characterized by the stable separation properties. The representative results are presented in Fig. 3 and Table 4.

Applied ceramic modules were characterized by a relatively high separation (82\%-92\%) of organic matter, expressed as COD. However the retention coefficients of COD during the filtration of solution B were slightly lower, and were in the range of $39 \%$ to $52 \%$. The COD reduction during filtration of solution $B$ was mainly related to the removal of milk components (lactose and protein), and to a lesser extent to the removal of organic compounds of the single-phase detergent.

The content of the protein and the lactose in solution B treated by means of ceramic modules was of very low concentration. This indicates that the recovered permeate has the similar quality as the pure detergent. It was shown that separation efficiency of lactose, because of its low molecular weight, was significantly dependent on the cut-off value of the module and as well as on the $\mathrm{pH}$ of the feed solution. The retention of lactose on UF modules amounted to 59\%-99\% and 92\%-100\% during filtration of Solutions A and B, respectively.

The concentration of $\mathrm{NaOH}$ in the permeates was slightly lower than in the feed solution, and thus affecting the lower conductivity and $\mathrm{pH}$ of the treated solutions. Moreover, a slight increase in surface tension of the permeates was noticed. For Solution A, it was most likely caused by the separation of peptides, which according to literature data have the ability to lower the surface tension of solutions. However, for Solution B, the surface tension determined in the permeate was the result of separation of the components that lowered the surface tension of liquids, such as peptides, anionic surfactants and EDTANa $a_{4}$. It should also be noted that during filtration runs the lowest retention coefficients and the highest permeability were achieved by module with the lowest cut-off value (1 kDa) (Table 1 and 4). It was probably associated with a larger diameter of the membrane's pores, than that declared by the manufacturer. Literature reports confirm [12] that membrane formation with adequate pore size in sieving layer is much more difficult with the use of ceramics in comparison with polymeric materials.

In the next stage of research, the impact of the process parameters (transmembrane pressure, cross-flow velocity at the membrane's surface and temperature) on the efficiency of the UF process was determined. The test results for the module of $5 \mathrm{kDa}$ are shown in Table 5.

With the increase of the TMP, a distinct growth of the permeate flux occurred. Due to the increase in the permeate flux, the effect of the polarisation layer on the membrane surface was more pronounced and the more intensive transport of the components through the membrane's active layer took place. It resulted in the increase mainly of the concentration of the low molecular weight compounds in the permeate. Similar results were observed for the temperature tests. However, the increase of permeate flux was mainly associated with the decrease in viscosity of the solution. On the other hand, the improvement of the separation properties with an increase in the cross-flow velocity was obtained through more effective control of the polarisation layer thickness. 

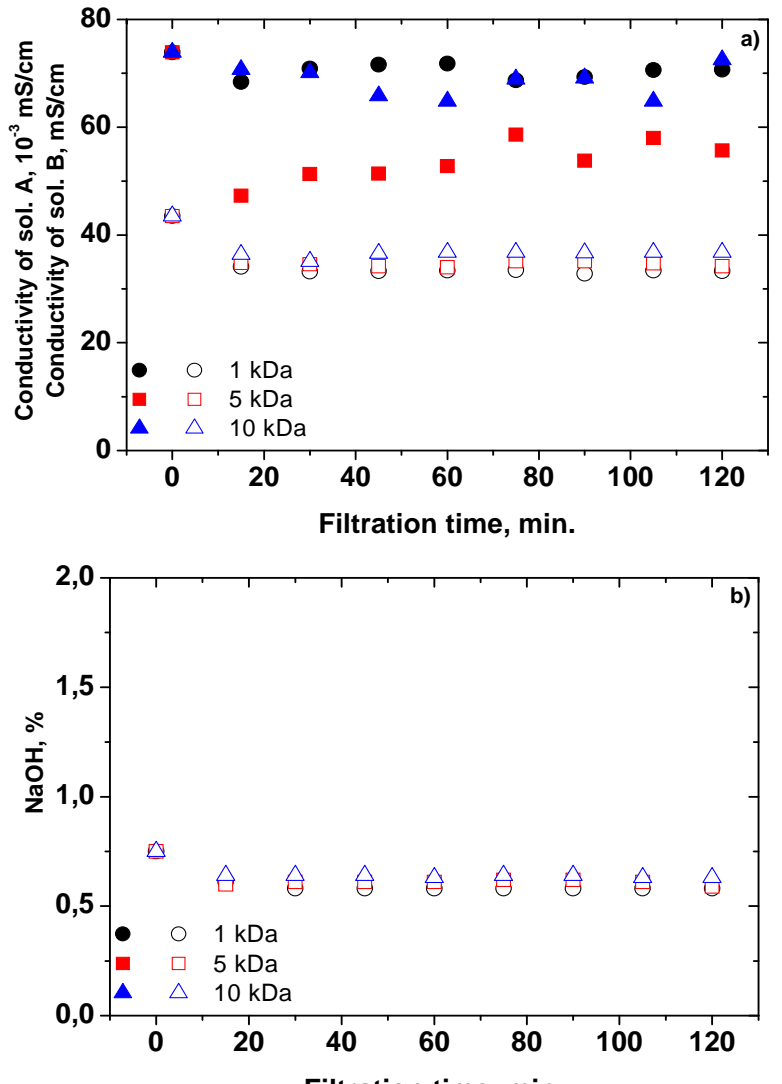

Filtration time, min.
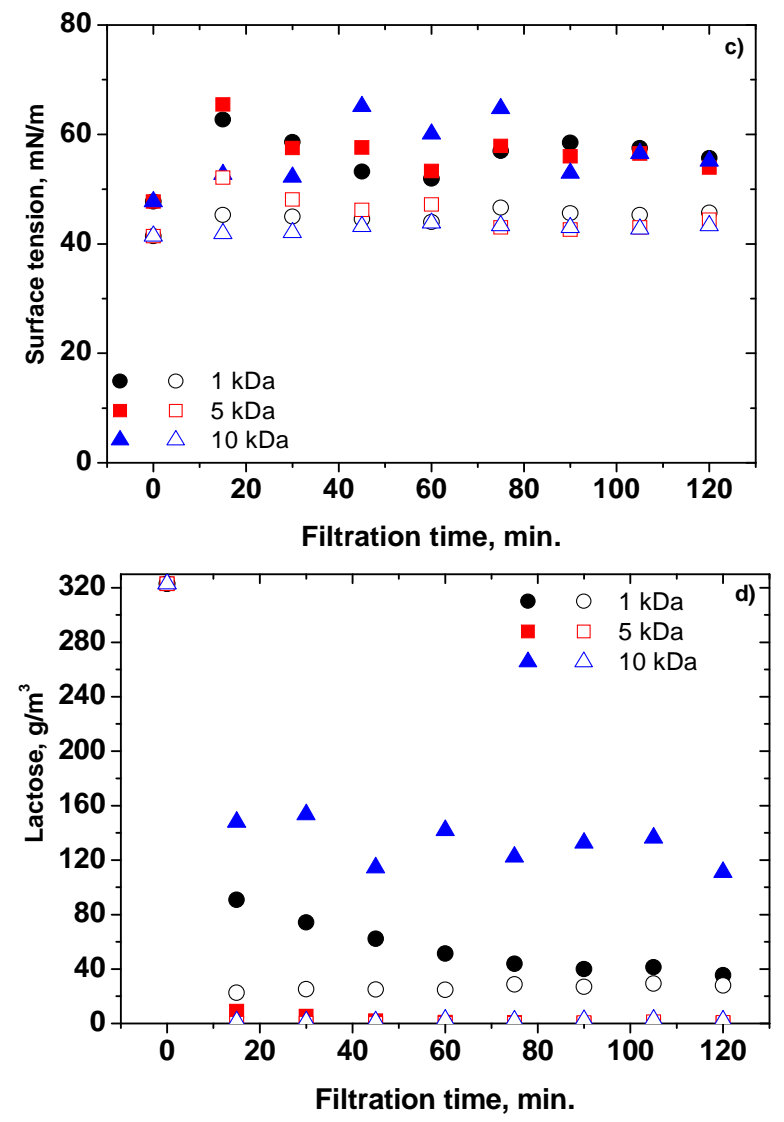
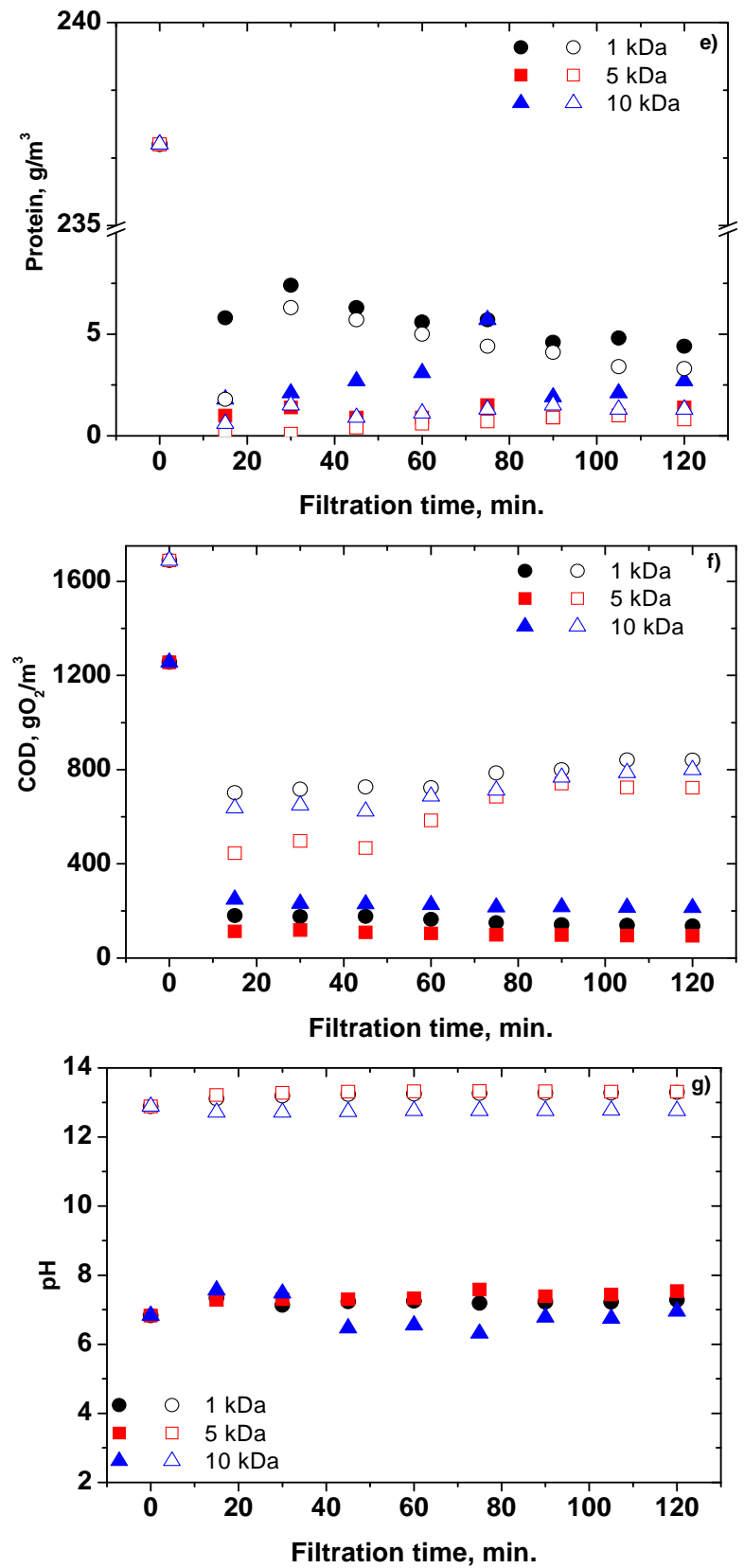

Fig. 3 Changes in the quality of solution A (full symbols) and solution $B$ (open symbols) in membrane filtration. Process parameters: $1 \mathrm{kDa}$ : TMB $=3 \mathrm{bar}, \mathrm{CFV}=6.3 \mathrm{~m} / \mathrm{s} ; 5$ kDa: $\mathrm{TMB}=3 \mathrm{bar}, \mathrm{CFV}=2.5 \mathrm{~m} / \mathrm{s} ; 10 \mathrm{kDa}: \mathrm{TMB}=2 \mathrm{bar}$, CFV $=6.3 \mathrm{~m} / \mathrm{s}$.

\section{Conclusions}

The research performed has shown the usefulness of the ceramic modules for regeneration of the spent single-phase detergent. The modules in a long-term filtration regime, due to their hydrophilic nature, were characterized by relatively low susceptibility to fouling. 
Table 4 Retention coefficients ( $R$, \%) of organic compounds on ceramic modules*.

\begin{tabular}{llrlrrrr}
\hline Cut-off $(\mathrm{kDa})$ & \multicolumn{3}{c}{ Solution A } & & \multicolumn{3}{c}{ Solution B } \\
\cline { 2 - 3 } \cline { 6 - 8 } & Lactose & \multicolumn{1}{c}{ Protein } & COD & & Lactose & \multicolumn{1}{c}{ Protein } & COD \\
\hline 1 & $83 \pm 5.6$ & $98 \pm 0.4$ & $87 \pm 1.4$ & & $92 \pm 0.7$ & $98 \pm 0.6$ & $39 \pm 4.2$ \\
5 & $99 \pm 1.0$ & $100 \pm 0.1$ & $92 \pm 0.7$ & & $100 \pm 0.1$ & $100 \pm 0.1$ & $52 \pm 9.3$ \\
10 & $59 \pm 4.5$ & $99 \pm 0.5$ & $82 \pm 0.9$ & & $99 \pm 0.2$ & $99 \pm 0.1$ & $44 \pm 5.2$ \\
\hline
\end{tabular}

* mean value \pm standard deviation.

Table 5 The effect of process parameters on separation properties of $5 \mathrm{kDa}$ module.

\begin{tabular}{|c|c|c|c|c|c|c|c|}
\hline Temp. $\left({ }^{\circ} \mathrm{C}\right)$ & $\begin{array}{l}\text { TMP } \\
\text { (bar) }\end{array}$ & $\begin{array}{l}\mathrm{CFV} \\
\left(\mathrm{m} \cdot \mathrm{s}^{-1}\right)\end{array}$ & $\begin{array}{l}\text { Cond } \\
\left(\mathrm{m} \cdot \mathrm{S} \cdot \mathrm{cm}^{-1}\right)\end{array}$ & $\begin{array}{l}\mathrm{NaOH} \\
(\%)\end{array}$ & $\begin{array}{l}\text { Surf. tension } \\
\left(\mathrm{mN} \cdot \mathrm{m}^{-1}\right)\end{array}$ & $\begin{array}{l}\text { Lactose } \\
\left(\mathrm{g} \cdot \mathrm{m}^{-3}\right)\end{array}$ & $\begin{array}{l}\text { Protein } \\
\left(\mathrm{g} \cdot \mathrm{m}^{-3}\right)\end{array}$ \\
\hline \multirow{4}{*}{20.0} & 1 & \multirow{4}{*}{7.6} & 34.6 & 0.62 & 41.2 & 0.2 & 0.9 \\
\hline & 2 & & 34.8 & 0.62 & 42.3 & 0.6 & 1.1 \\
\hline & 3 & & 35.1 & 0.62 & 41.9 & 1.2 & 1.4 \\
\hline & 4 & & 35.2 & 0.62 & 44.8 & 1.8 & 1.7 \\
\hline \multirow{3}{*}{20.0} & \multirow{3}{*}{1.5} & 4.8 & 35.1 & 0.62 & 44.7 & 1.8 & 1.3 \\
\hline & & 8.2 & 34.9 & 0.62 & 40.6 & 2.0 & 1.7 \\
\hline & & 10.5 & 34.7 & 0.62 & 40.6 & 1.7 & 0.8 \\
\hline 43.3 & \multirow{8}{*}{3.0} & \multirow{8}{*}{4.2} & 37.0 & 0.68 & 48.2 & 15.5 & 2.4 \\
\hline 42.5 & & & 37.3 & 0.67 & 47.5 & 14.8 & 2.4 \\
\hline 37.0 & & & 36.8 & 0.67 & 47.1 & 12.9 & 2.1 \\
\hline 32.0 & & & 36.1 & 0.65 & 46.5 & 10.8 & 1.9 \\
\hline 28.5 & & & 35.9 & 0.66 & 44.9 & 8.6 & 1.7 \\
\hline 26.8 & & & 35.9 & 0.65 & 43.7 & 7.4 & 1.9 \\
\hline 24.0 & & & 35.9 & 0.66 & 42.7 & 6.5 & 1.7 \\
\hline 21.3 & & & 34.8 & 0.65 & 43.2 & 2.7 & 1.6 \\
\hline
\end{tabular}

Rinsing modules with deionized water after filtration helped significantly to restore their original permeability or caused even an increase of water flux in comparison with the stream of deionized water.

The recovered spent detergent maintained its basic cleaning properties, i.e., high $\mathrm{pH}$, high concentration of $\mathrm{NaOH}$ and low value of surface tension. Moreover, the ceramic modules showed high retention of specific milk components (protein and lactose) and organic matter expressed as COD. It has been shown that the transport and separation properties of the modules were dependent on the process parameters, such as TMP, CFV and temperature.

\section{References}

[1] N.M.D. Souza, A.J. Mawson, Membrane cleaning in the dairy industry: A review, Critical Reviews in Food Science and Nutrition 45 (2005) 125-134.

[2] P. Fernández, F.A. Riera, R. Álvarez., S. Álvarez, Nanofiltration regeneration of contaminated single-phase detergents used in the dairy industry, Journal of Food Engineering 97 (2010) 319-328.

[3] S. Novalic, A. Dabrowski, K.D. Kulbe, Nanofiltration of caustic soda and acidic cleaning solutions with high COD: Part 1. Recycling of sodium hydroxide, Journal of Food Engineering 38 (1998) 125-132.

[4] S. Novalic, A. Dabrowski, K.D. Kulbe, Nanofiltration of caustic soda and acidic cleaning solutions with high COD: Part 1. Recycling of $\mathrm{HNO}_{3}$, Journal of Food Engineering 38 (1998) 133-140.

[5] M. Dresch, G. Daufin, B. Chaufer, Integrated membrane regeneration process for dairy cleaning-in-place, Separation and Purification Technology 22-23 (2001) 181-191.

[6] G. Gésan-Guiziou, E. Boyaval, G. Daufin, Nanofiltration for the recovery of caustic cleaning-in-place solutions: Robustness towards large variations of composition, Desalination 149 (2002) 127-129.

[7] G. Trägårdh, D. Johansson, Purification of alkaline cleaning solutions from the dairy industry using membrane separation technology, Desalination 119 (1998) 2-29.

[8] G. Daufin, J.P. Escudier, H. Carrere, S. Berot, L. Fillaudeau, $\mathrm{M}$. Decloux, Recent and emerging applications of membrane processes in the food and dairy industry, Chemical 
Engineering Research and Design 79 (2001) 89-102.

[9] M. Dresch, G. Daufin, B. Chaufer, Membrane processes for the recovery of dairy cleaning-in-place solutions, Lait 79 (1999) 245-259.

[10] I. Kowalska, An assessment of the cleaning solutions' purification by membrane filtration, Desalination and Water Treatment 51 (2013) 1366-1376.

[11] Y.K. Erdem, Z. Yuksel, Sieving effect of heat-denatured milk proteins during ultrafiltration of skim milk. I. The preliminary approach, Journal of Dairy Science 88 (2005) 1941-1946.

[12] J. Kim, B. van der Bruggen, The use of nanoparticles in polymeric and ceramic membrane structures: Review of manufacturing procedures and performance improvement for water treatment, Environmental Pollution 158 (2010) 2335-2349. 